\title{
Lina Gafner
}

\section{Schreibarbeit}

Die alltägliche Wissenspraxis eines Bieler Arztes im 19. Jahrhundert

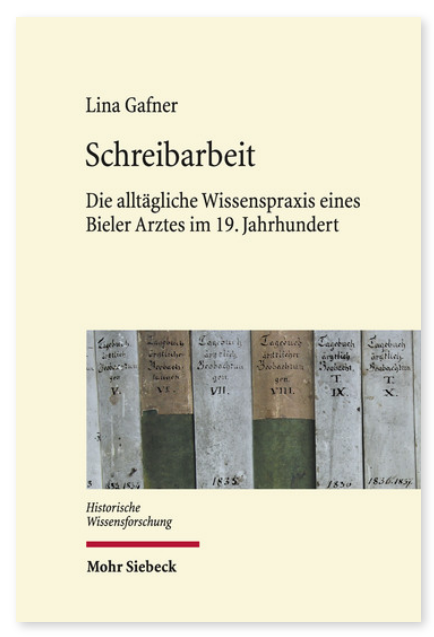

2016. X, 290 Seiten. HWF 7

ISBN 978-3-16-154909-0

DOI 10.1628/978-3-16-154909-0

eBook PDF 74,00€

ISBN 978-3-16-154908-3

Festeinband $74,00 €$
Wie wurden Ärzte im 19. Jahrhundert, vor der Einführung der Bakteriologie und damit vor dem Beginn der »modernen Medizin«, zu unentbehrlichen Experten? Und welche Rolle spielte dabei die ärztliche Schreibarbeit? Der Bieler Arzt und Politiker Cäsar Bloesch (1804-1863) hat 55 Journalbände hinterlassen. Konsultationen, Zeugnisse, Gutachten und Impftabellen, aber auch Beobachtungen des Wetters und des Gesundheitszustands der Bevölkerung sind darin abgelegt. Anhand dieser Schreibformate zeigt Lina Gafner, wie die ärztliche Buchführung in den Kontext politischer Konflikte, standespolitischer Interessen, wissenschaftlicher Kontroversen und bürgerlich-männlichen Selbstverständnisses zu stellen ist. Dadurch wird erstmals deutlich, wie ärztliches Denken und ärztliche Praxis im 19. Jahrhundert von den Ansprüchen des modernen Verwaltungsstaates geprägt wurden und wie sich die Ärzte über ihre Schreibarbeit einen zentralen Platz in Staat und Gesellschaft erarbeiteten.

Lina Gafner Geboren 1982; Studium der Geschichte, Philosophie und deutschen Literatur an der Universität Bern; Doktorat in Bern und Zürich; derzeit im Mutterschaftsurlaub. Co-Leitung Stadt.Geschichte.Basel, Universität Basel.

Jetzt bestellen:

https://mohrsiebeck.com/buch/schreibarbeit-9783161549090?no_cache=1

order@mohrsiebeck.com

Telefon: +49 (0)7071-923-17

Telefax: +49(0)7071-51104 